\title{
Thermal decomposition of layered double hydroxide as a bottom up approach for the synthesis of metallic nanoparticles embedded in carbon structures
}

Caroline Silva de Matos, ${ }^{a}$ Camélia Matei Ghimbeu, ${ }^{b, c}$ Jocelyne Brendlé, ${ }^{b, c}$ Lionel Limousy $^{\mathrm{b}, \mathrm{c}}$ and Vera Regina Leopoldo Constantino*a

\footnotetext{
a Departamento de Química Fundamental, Instituto de Química da Universidade de São Paulo, Av. Prof. Lineu Prestes 748, CEP 05508-000 - São Paulo, SP, Brazil * vrlconst@iq.usp.br

${ }^{b}$ Institut de Science des Matériaux de Mulhouse, Université de Haute-Alsace, CNRS UMR 7361, 15 rue Jean Starcky, 68057 Mulhouse Cedex

c Université de Strasbourg, 67000 Strasbourg, France
}

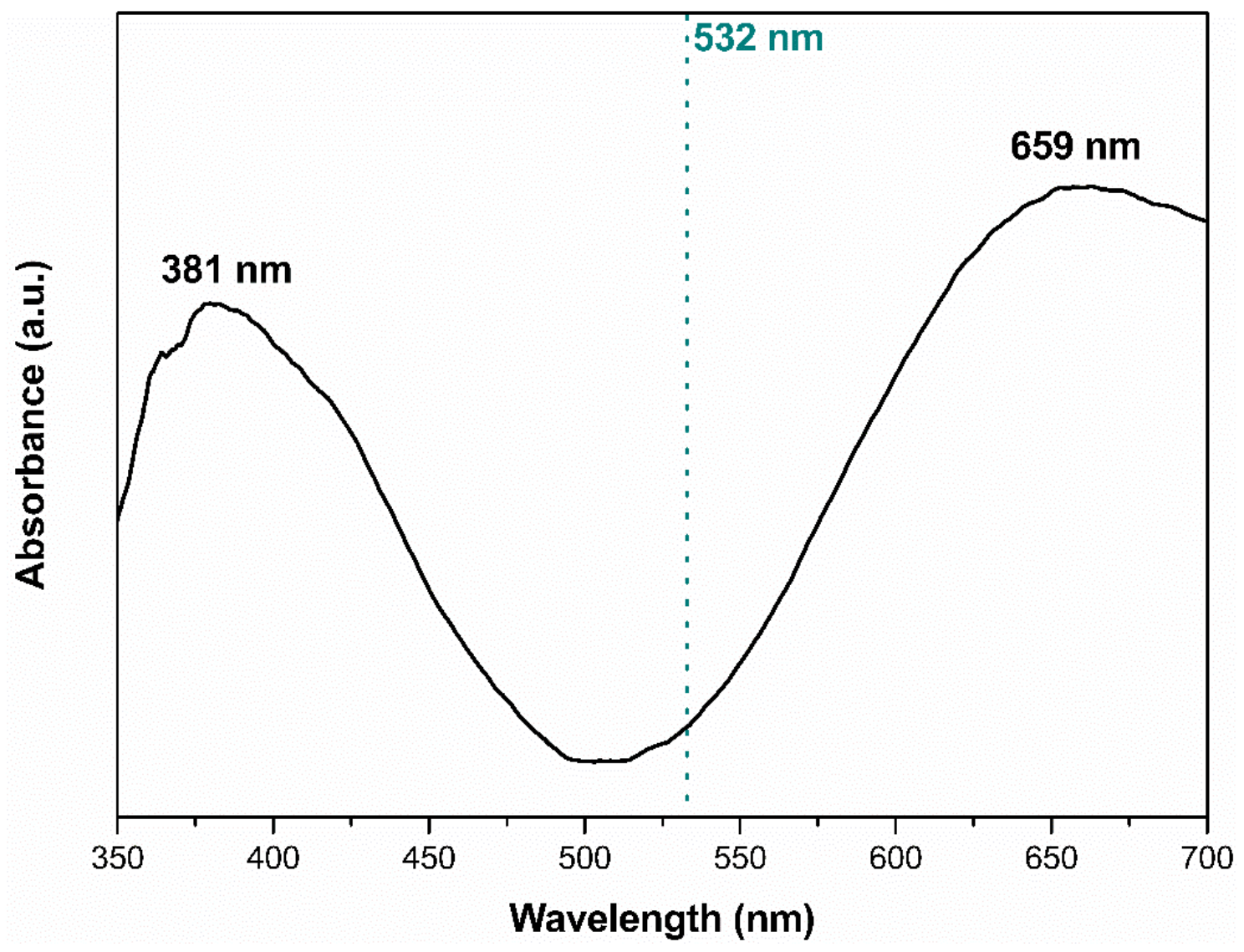

Fig. S1 Ultraviolet-visible electronic absorption spectrum of $\mathrm{LDH}-\mathrm{Cl}$ (curve smoothed by Adjacent-Averaging method). The material was mixed with barium sulfate $\left(\mathrm{BaSO}_{4}\right)$ and the solid state spectrum recorded in spectrophotometer Shimadzu UV-2401PC eqquiped with a integrating sphere. 


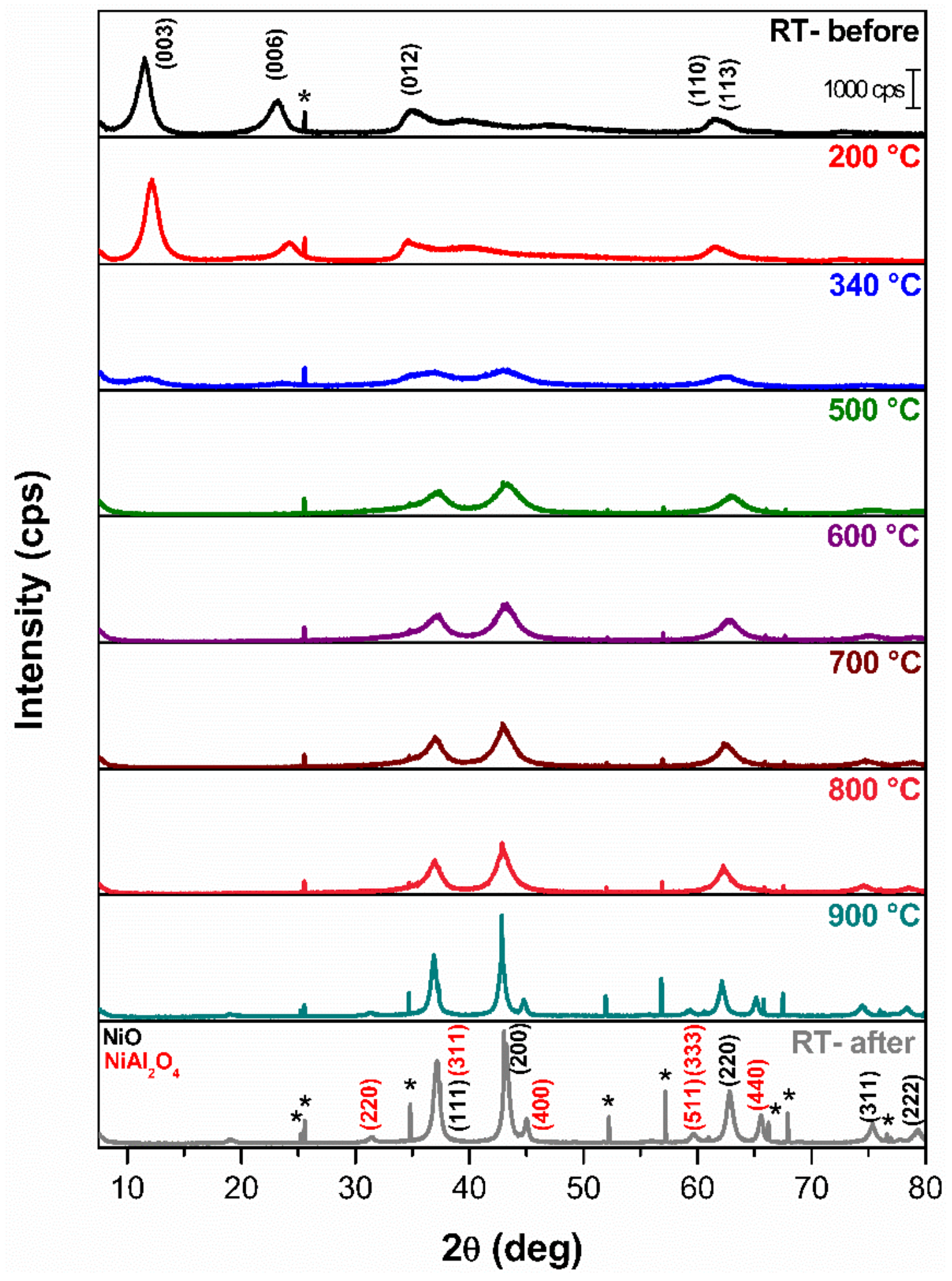

Fig. S2 HT-XRD patterns of $\mathrm{LDH}-\mathrm{Cl}$ recorded under He atmosphere, under same conditions used for LDH-CMC sample. * sample holder. 


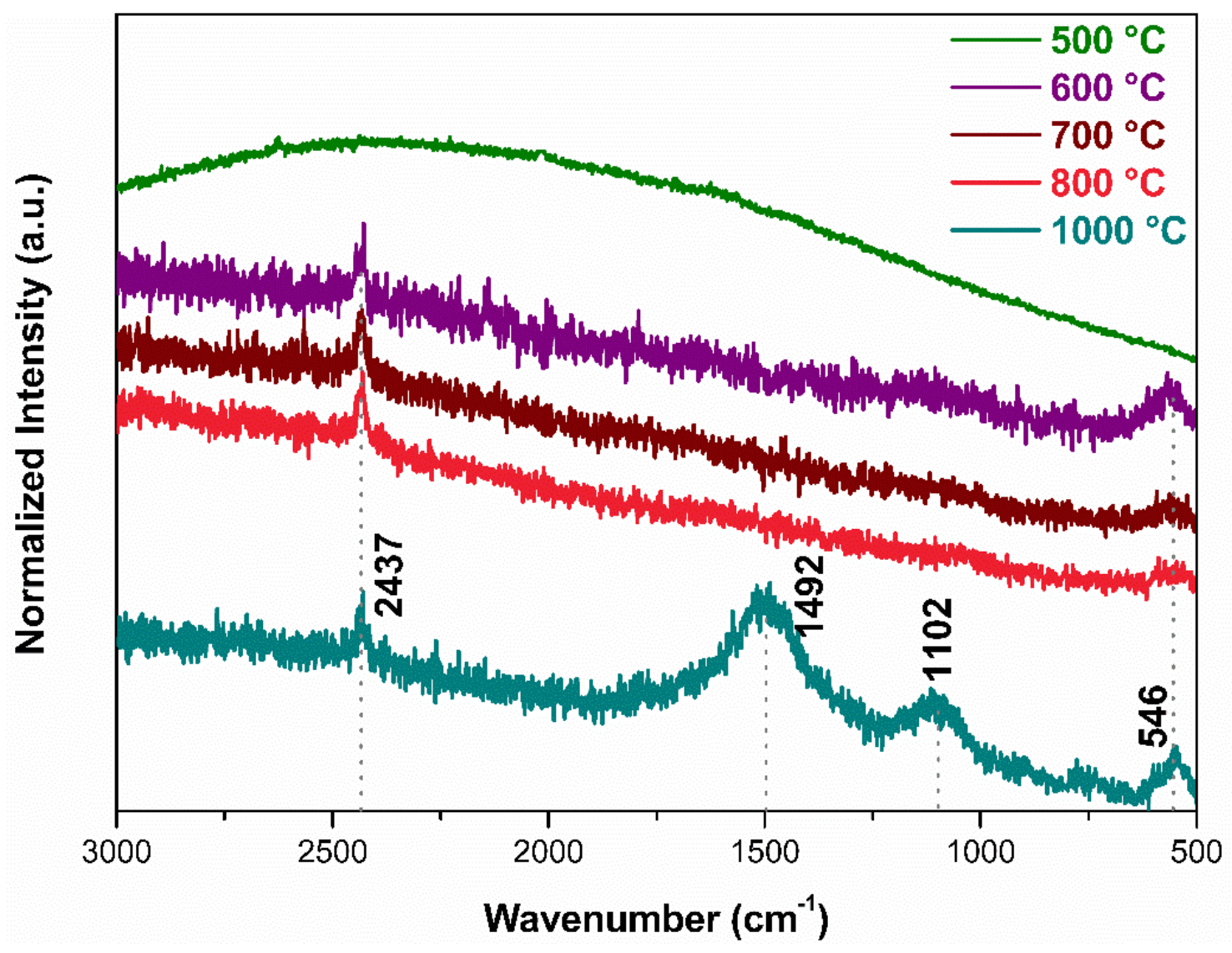

Fig. S3 Raman spectra of LDH-Cl-X series recorded using $\lambda_{\text {ex }}$ of $532 \mathrm{~nm}$. 


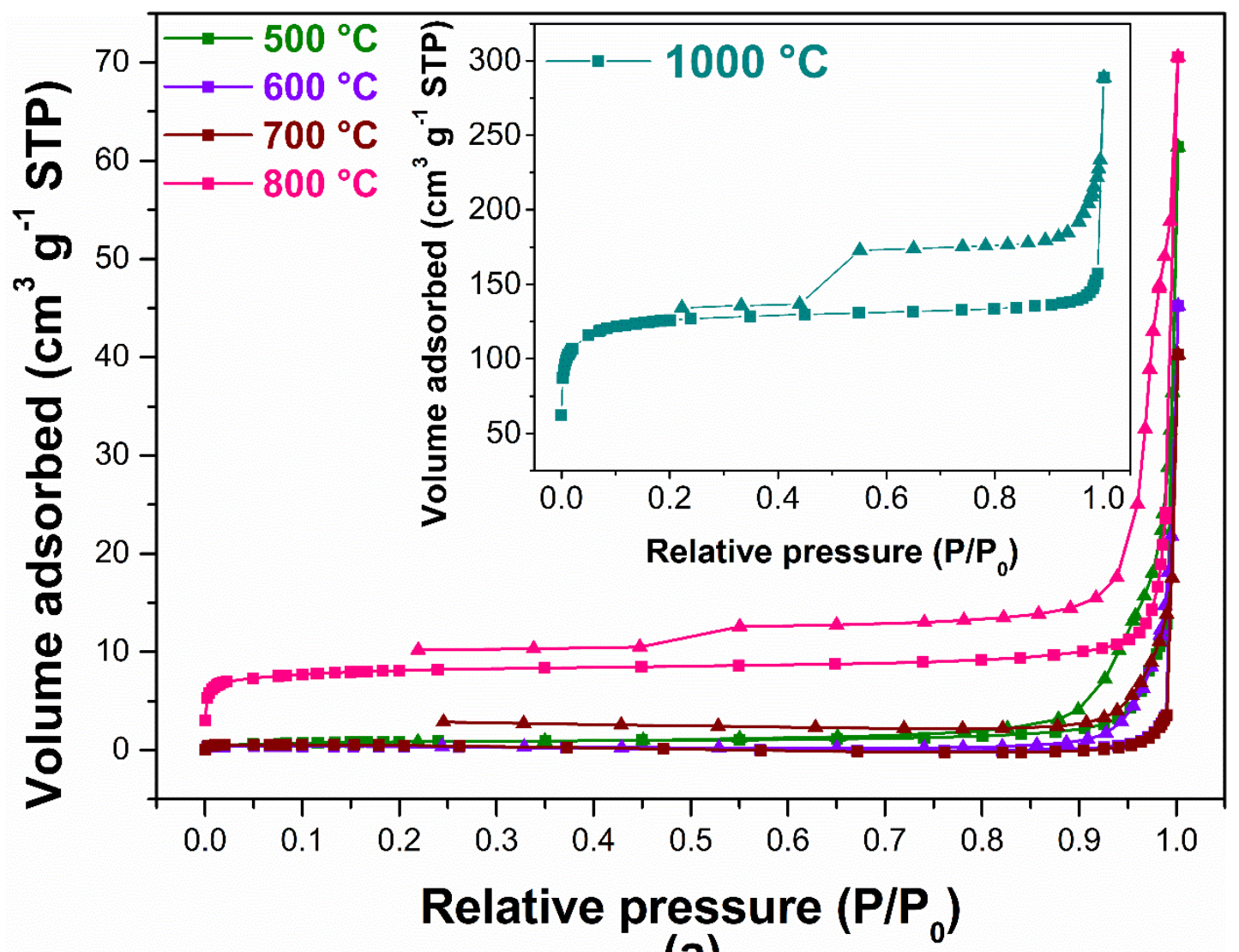

(a)

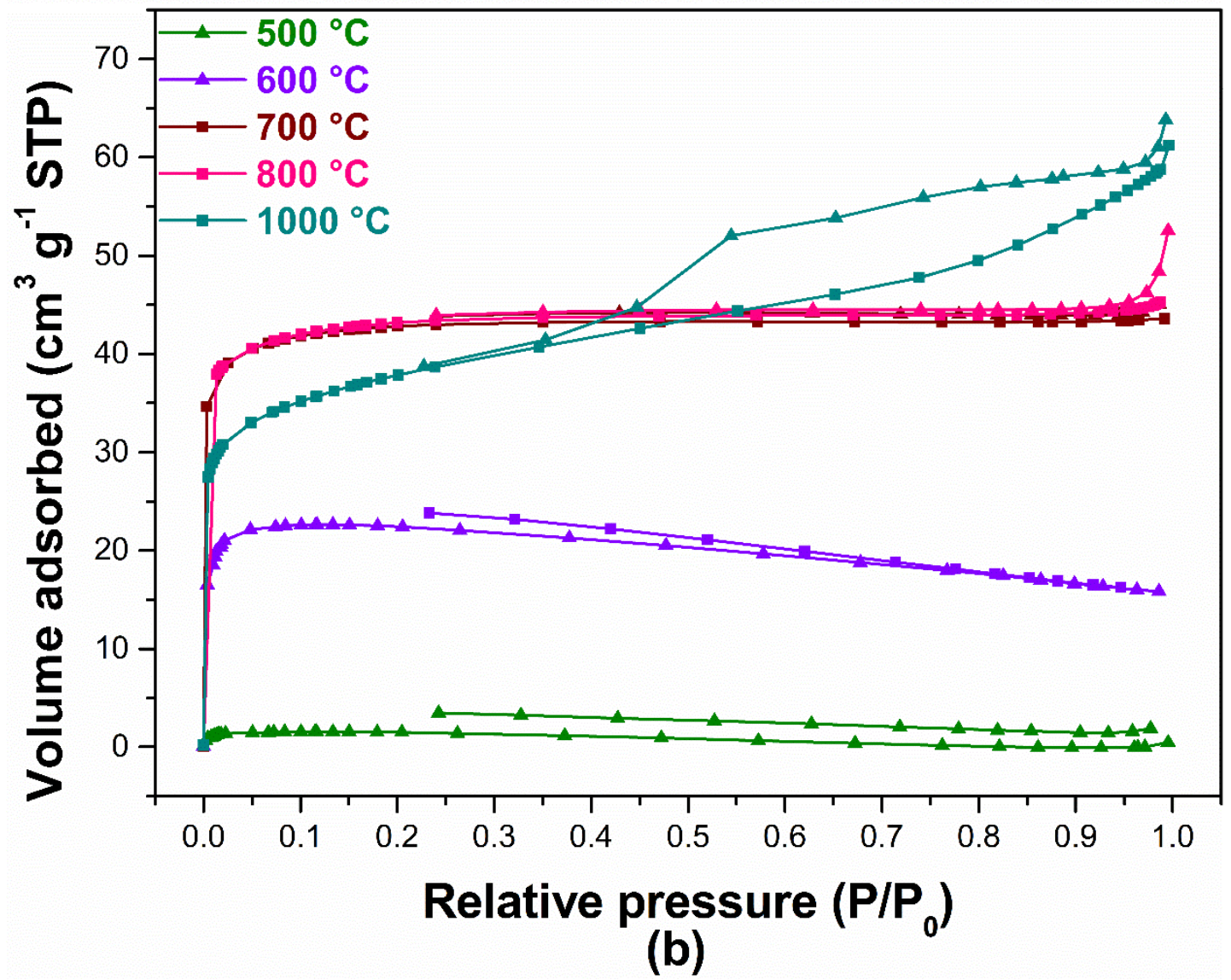

Fig. S4 $\mathrm{N}_{2}$-adsorption/desorption isotherms of CMC-X (a) and LDH-CMC-X (b) samples series. Inset shows the curve of CMC- 1000 . 


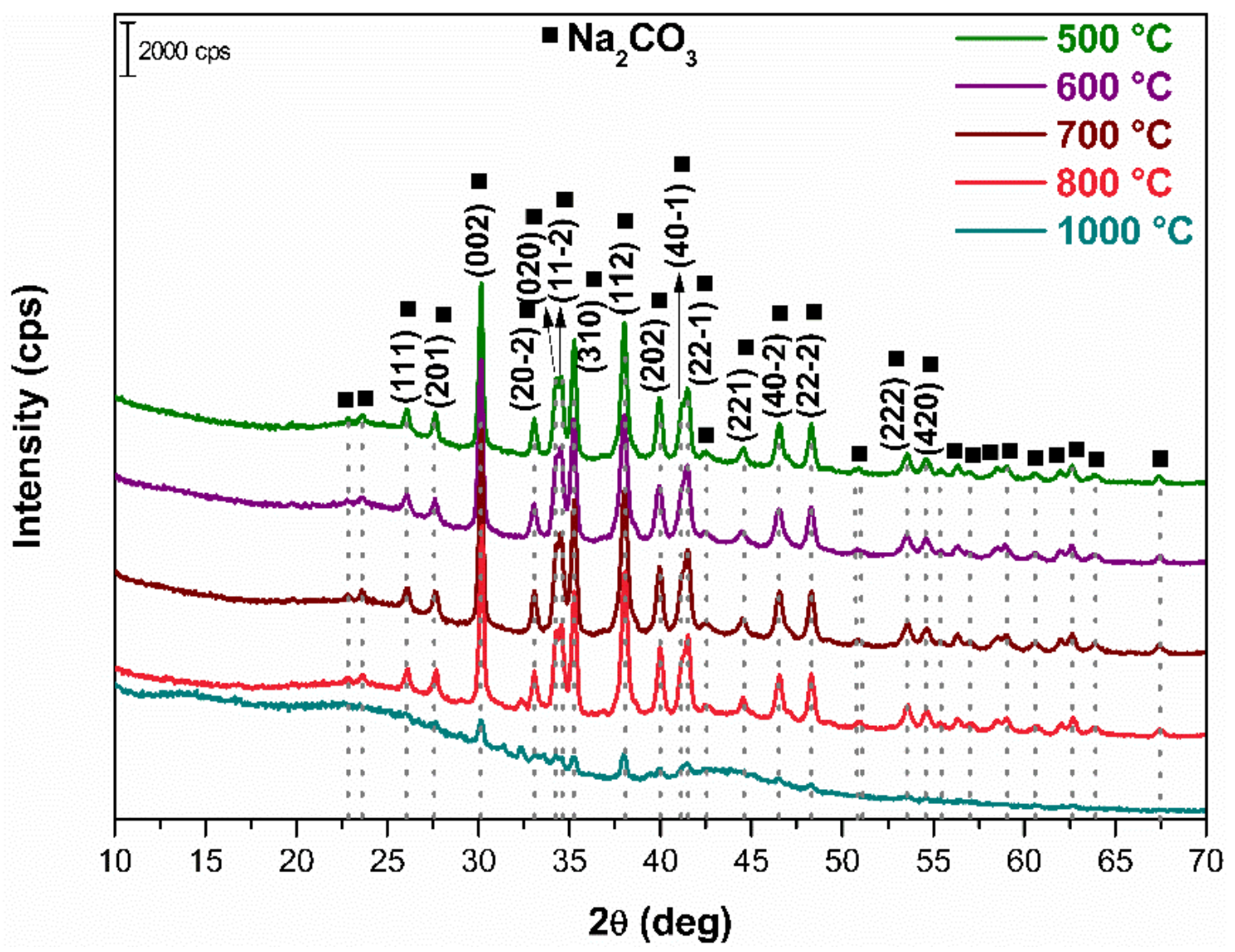

Fig. S5 XRD patterns of CMC-X materials pyrolyzed at the indicated temperature value. 


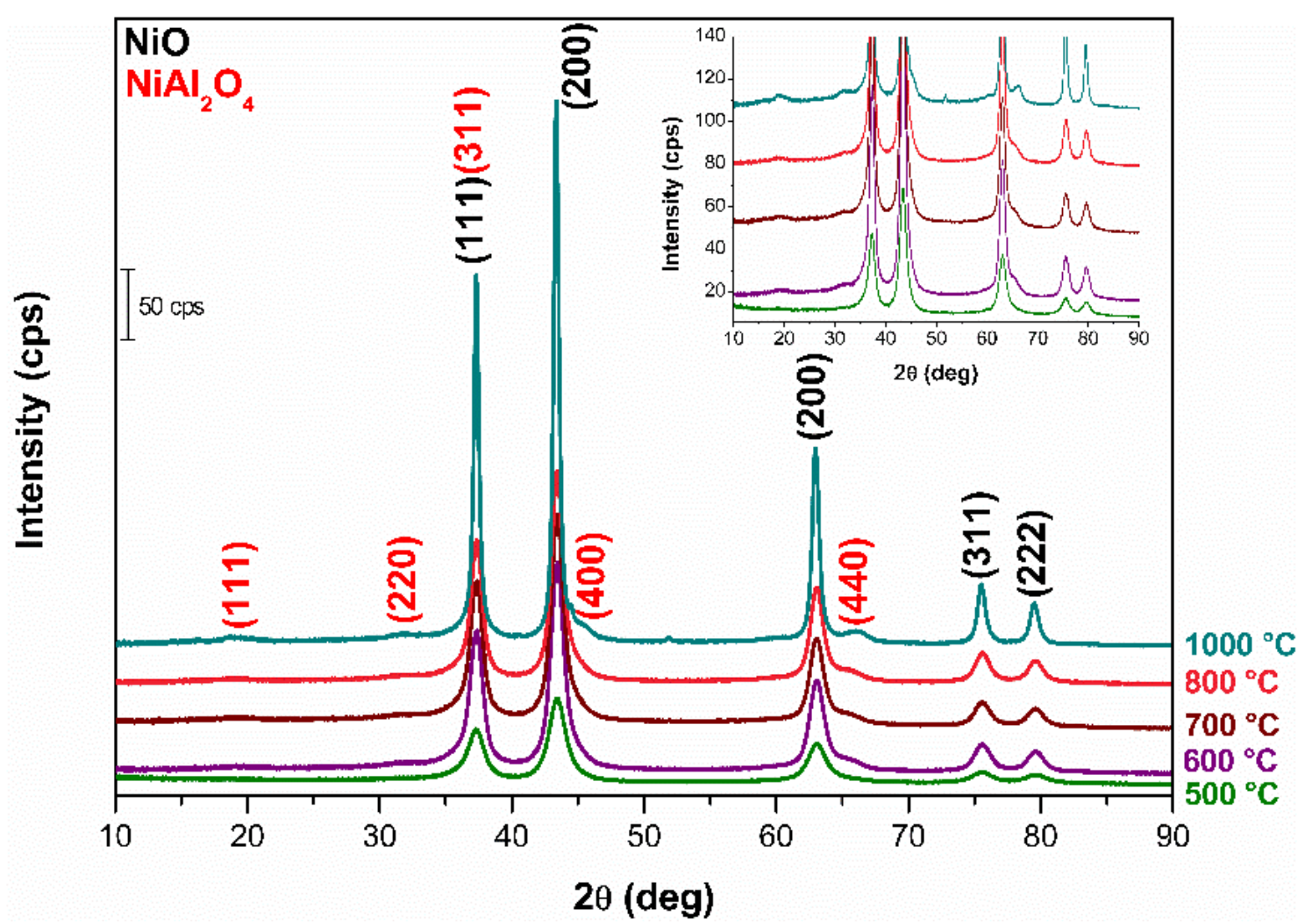

Fig. S6 XRD patterns of residues from LDH-CMC-X thermal analysis under air atmosphere. Inset: detailed diffractograms.

Table S1 LDH-CMC-X residual mass from TG curves recorded under air atmosphere and experimental mass percentages of nickel and carbon.

\begin{tabular}{cccc}
\hline $\begin{array}{c}\text { Pyrolysis } \\
\text { temperature } \\
\left({ }^{\circ} \mathbf{C}\right)\end{array}$ & $\begin{array}{c}\text { Residual mass }^{\mathbf{a}} \\
\mathbf{( \% )}\end{array}$ & $\mathbf{\% N i}^{\mathbf{b}}$ & $\mathbf{\% C}^{\mathbf{c}}$ \\
\hline $\mathbf{6 0 0}$ & 81.4 & 21.5 & 13.7 \\
$\mathbf{7 0 0}$ & 83.9 & 24.1 & 14.3 \\
$\mathbf{8 0 0}$ & 85.8 & 25.5 & 13.6 \\
$\mathbf{1 0 0 0}$ & 92.1 & 39.0 & 13.1 \\
\hline
\end{tabular}

${ }^{\text {a }}$ Values obtained in the $200-900^{\circ} \mathrm{C}$ range, in order to discount mass loss from dehydration process.

${ }^{\mathrm{b}}$ Values estimated from magnetization saturation $\left(M_{S}\right)$ of bulk nickel $\left(55.1 \mathrm{emu} \mathrm{g}^{-1}\right),{ }^{1}$ and the corresponding values of each sample (see Fig. S6), calculated by: $\% N i=\frac{M_{S}}{M_{S(b u l k)}} \cdot 100 \%$. ${ }^{c}$ Data from elemental chemical analysis. 


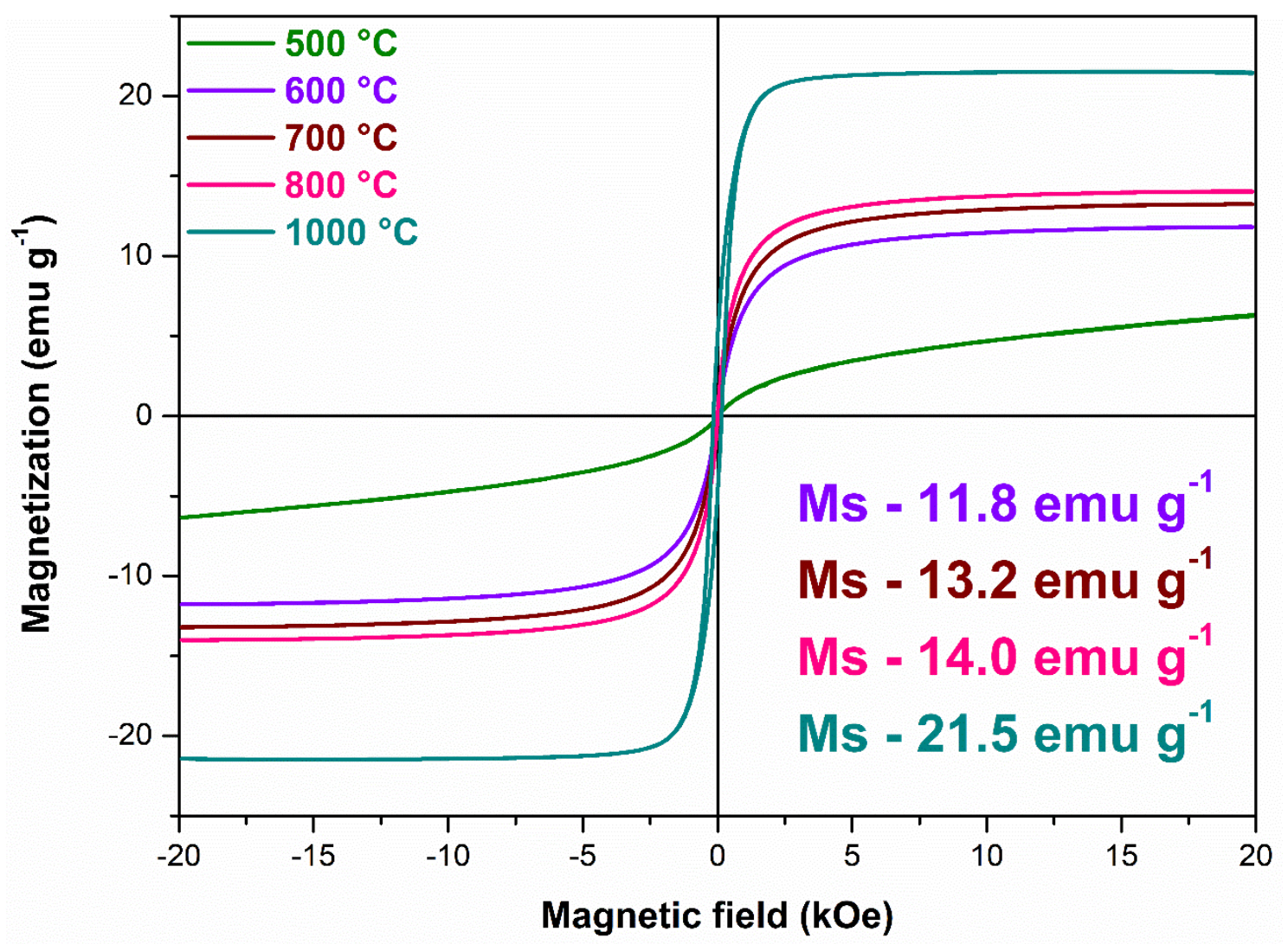

Fig. S7 LDH-CMC-X magnetization curves recorded at room temperature, containing the values of saturation magnetization (Ms) for the materials pyrolyzed from 600 to 1000 ${ }^{\circ} \mathrm{C}$. The magnetization values were normalized by total mass of each material.

\section{Reference}

1 J. Crangle and G. M. Goodman, Proc. R. Soc. A Math. Phys. Eng. Sci., 1971, 321, 477-491. 